\title{
THE ROLE OF PERCEIVED BENEFITS IN FORMATION OF INTENTION TO USE ISLAMIC CROWDFUNDING PLATFORM AMONG SMALL AND MEDIUM ENTERPRISES IN MALAYSIA
}

\author{
Maizaitulaidawati Md Husin 1 \\ Azman Hashim International Business School, \\ Universiti Teknologi Malaysia, Kuala Lumpur, Malaysia. \\ (Email: maizaitulaidawati@gmail.com) \\ Razali Haron ${ }^{2}$ \\ IIUM Institute of Islamic Banking and Finance, \\ International Islamic University Malaysia, Kuala Lumpur, Malaysia. \\ (Email: hrazali@iium.edu.my) \\ Shahab Aziz ${ }^{3}$ \\ Management Science Department, Bahria University, Islamabad, Pakistan. \\ (Email: shahabaziz7@hotmail.com)
}

Received date: 04-07-2019

Revised date: 19-08-2019

Accepted date: 20-08-2019

Published date: 15-09-2019

To cite this document: Md Husin, M., Haron, R., \& Aziz, S. (2019). The Role of Perceived Benefits in Formation of Intention to Use Islamic Crowdfunding Platform among Small and Medium Enterprises in Malaysia. International Journal of Entrepreneurship and Management Practices, 2 (7), 39-47.

DOI: $10.35631 / \mathrm{ijemp} .27005$

\begin{abstract}
Crowdfunding has become global phenomenon due to its possible role in providing equity funding to small and medium enterprises. Numerous benefits of crowdfunding have been identified. This paper investigated whether three factors - economic benefit, convenience and transaction process are important in influencing the perceived benefits of Islamic crowdfunding platforms, and whether perceived benefits affect small and medium enterprises' (SMEs) intention to use the platform. Self-administered questionnaires and structured online surveys were distributed to SMEs in Selangor, Malaysia using the purposive sampling technique. SmartPLS was used to analyse the data. This paper found that economic benefit has a positive and significant relationship with perceived benefits, and transaction process has a negative and significant relationship with perceived benefits, while convenience was found to have an insignificant relationship with perceived benefits. This paper also found that perceived benefits was found to have a significant relationship with intention. The significance and contribution of this paper were also discussed.
\end{abstract}

Keywords: Islamic Crowdfunding, SMEs, Fintech, Perceived Benefits, Intention 


\section{Introduction}

Small and Medium-Sized Enterprises (SMEs) play a significant role in enhancing the economic growth of a country. Their role in boosting the production of goods and services, reducing unemployment, contributing to import and exports activities, facilitating equitable distribution of income, and supporting social cohesion is very critical. In Malaysia, the government is very supportive of supporting SME businesses. SMEs are supported with comprehensive policy development, sustainable environment, and effective monitoring to ensure their businesses' sustainability. However, despite the favourable environment and encouragement from the government, SMEs around the globe including those in Malaysia face difficulties in securing financing, especially bank loan financing. According to The Organisation for Economic Co-operation and Development (OECD) (2018), access to finance is one of the main factors that hinder the SMEs' development around the globe, especially young firms and start-ups, micro-enterprises, and innovative ventures.

As financing is one of the important elements for SME sustainability, access to financing is thus being re-shaped with focus shifting to the development of more non-traditional financing avenues and financial technology (Fintech) platforms such as crowdfunding, peer-to-peer financing, venture capital and angel investors (SME, 2016). According to Dominika and Michat (2018), the emergence of Fintech and crowdfunding is important for start-ups and SMEs as their access to traditional forms of financing such as bank lending, business angels and venture capital investments are limited. However, according to Zahid (2018), almost 60\% of SMEs still use conventional financing rather than crowdfunding to raise funding. This leads to the question on whether potential users, in this case SMEs are aware of the benefits of using this platform. As understanding the factors that influence the perceived benefits of potential users is important in determining their intention to use such platform, this study identifies the relevant drivers that may influence the SMEs' perceived benefits of using crowdfunding platforms.

\section{Literature Review}

\section{Financial Technology and Islamic Crowdfunding Platforms}

Financial technology (Fintech) has emerged to become a popular term that describes novel technologies that are useful to improve and automate the process of delivering and transferring money. Over the past few years, Fintech activities have reached a remarkable volume. As of March 2018, global investment in Fintech companies has hit US\$57.9 billion where the United States contributes US\$14.2billion and Europe contributes \$26billion to the total investment volume (KPMG, 2018). Crowdfunding, one of the elements in Fintech, has also evolved into a leading trend as a platform for start-ups and SMEs to acquire funding (Gałkiewicz and Gałkiewicz, 2018; Dietrich and Amrein, 2017). Crowdfunding is a platform whereby "the crowd" contributes small amounts of money, typically via the internet and social networks to fund a project. In Malaysia, the Investment Account Platform (IAP) is a crowdfunding platform launched in February 2016 by six local Islamic banks upon approval from the Securities Commission of Malaysia. It is the first Islamic bank-intermediated, internet-based Islamic crowdfunding platform that combines the expertise of Islamic banks with the efficiency of technology to channel funds from investors to viable economic ventures (Lian, 2016; Alaa and Abbas, 2017). The IAP promotes risk-sharing financial transactions using the principle of Musharaka and Mudharaba and provides SMEs with a new source of enhanced access to funding for their business activities (Lian, 2016). 


\section{Intention to Use Islamic Crowdfunding Platforms}

The construct "intention to use" has numerously been used to predict actual usage behaviour. According to Fishbein and Ajzen (1975), intention indicates the probability of a person behaving in a certain way. In a study using the technology context, Tanduklangi (2017) adapted the construct to measure user intention of using e-learning technology. Alaeddin and Altounjy (2018) also adapted the intention construct to measure user intention to use cryptocurrency. This paper proposes that perceived benefit has a positive and significant relationship with intention to use Islamic crowdfunding platforms. It is postulated that the better SMEs' perceive the benefits of using Islamic crowdfunding platforms, the higher their intention to use the platform.

In addition, this paper investigates the positive and significant relationship among three identified factors; economic benefit, convenience and transaction process with the perceived benefits of using this type of platform.

\section{Effects of Perceived Benefit on Intention to Use Islamic Crowdfunding Platforms}

It has been argued that online users are likely to engage in behaviours upon which benefits exceed their costs (Oxera Economics Council, 2015). According to Ryu (2018a) who studied the benefit of Fintech adoption, perceived benefit is defined as users' perception of the potential that Fintech usage will result in a positive outcome. Perceived benefits have been utilised as a direct determinant of intention in many studies (Ryu, 2018; Lee, 2009; Akroush et al., 2018). For example, Akroush et al. (2018) studied the factors affecting consumers' purchasing intention towards energy- efficient products in Jordan. The study found that perceived benefits positively influence users' intention. With regards to intention to use IAP, this paper suggests that perceived benefits of Islamic crowdfunding platforms positively impacts users' intention to use the IAP, thus the first hypothesis is formed.

\section{H1. Perceived benefit significantly influences intention to use investment account platform}

\section{Effects of Economic Benefit, Convenience and Transaction Process on Perceived Benefits}

An economic benefit can be quantified in terms of the amount of money that a firm generates, including net income and revenue. From the perspective of crowdfunding, the usage of online platforms for crowdfunding lowers the transaction and capital costs for SMEs, thereby benefiting the SMEs economically (Mackenzie, 2015; Oxera Economics Council, 2015). In addition, the convenience of using online platforms has been one of the most important stimulus underlying customers' preference to use the platform (Cho and Sagynov, 2015; Akturan and Tezcan, 2012; Oxera Economics Council, 2015). Smooth, prompt and efficient transaction processes are important in facilitating the crowdfunding online transaction process. According to (Ryu (2018a) and Abramova and Böhme (2016), the transaction process plays a key role in determining the perceived benefits of online platforms. With regards to the IAP, as SMEs promote their platforms easily via the website, it offers faster transaction than seeking financing from traditional financial institutions. Ryu (2018a) and Hsu and Bat-Erdene (2012) found a positive relationship between economic benefit, convenience and perceived benefits with perceived benefits. On the back of these evidences, this paper had formed the next three hypotheses; economic benefit, convenience and perceived benefits positively and significantly influence the perceived benefits of using Islamic crowdfunding platforms. To sum up, if SMEs perceive that using IAPs can offer them economic benefits, convenience to use and easy facilitation of the crowdfunding process, they 
will perceive the benefits of using these platforms; this subsequently affects their intention to use the platform. Accordingly, this paper postulated the following hypotheses:

$\mathrm{H} 2$. Economic benefit significantly influences perceived benefits

H3. Convenience significantly influences perceived benefits

H4. Transaction process significantly influences perceived benefits

\section{Conceptual Framework}

The conceptual framework is illustrated in Figure 1 below.

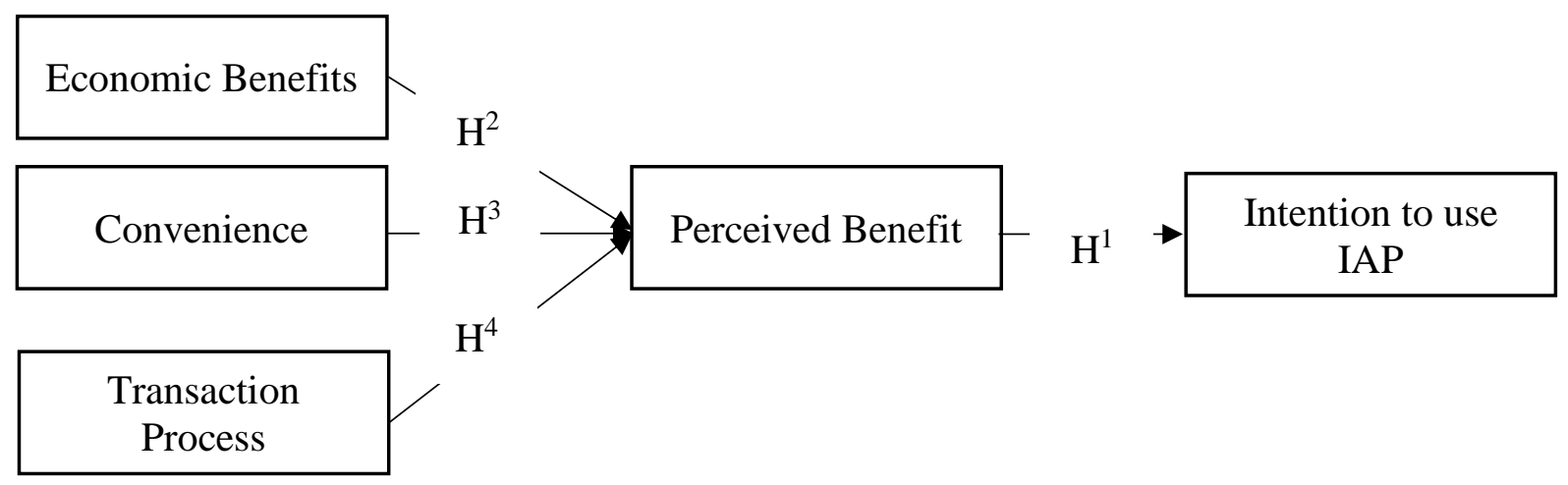

Figure 1. The Conceptual Framework

\section{Methodology}

To test the hypotheses, a questionnaire was developed and distributed to SMEs owners in Selangor, Malaysia using the purposive sampling technique. Selangor was chosen as it is Malaysia's richest (measured by GDP) and most populated state with the highest number of registered SMEs (OECD, 2018). 163 completed questionnaires were collected and analysed using Structural Equation Modelling via SmartPLS. The questionnaire was divided in two parts; Part A focusing on respondent's demographic information while part B consist of the five-point Likert scale questions measuring the variables used in this paper. All items intended to measure the constructs in this paper were adopted from the previously validated instruments and were modified to look at the fintech adoption intention.

36.2 per cent of the respondents came from small companies and 63.8 percent were from medium companies. In regards to funding sources, about 7.36 per cent of the companies obtained funding from individual investors and family offices, 12.88 per cent were funded by insurance companies, 15.95 per cent were funded by pension and provident funds, 15.34 per cent were funded by fund of funds and other asset managers, 24.54 per cent were funded by corporate investors, 12.88 per cent were funded by government agencies, 7.98 per cent were funded using sovereign wealth funds and government investment companies, and the remaining 3.07 per cent were obtained other sources of funds.

\section{Results}

Cronbach alphas were used to assess the reliability of items. The values of Cronbach alphas for all the items used exceeded the 0.7 threshold (Nunnally, 1987) thus displays how closely related the items are to its variable. In addition, this paper had also examined the average variance extracted. From the analysis, the average variance extracted was higher than 0.60 , 
thus meeting the requirement set by Fornell and Larcker (1981), except for transaction process. This indicates that the variance captured by each latent variable was significantly larger than the variance due to measurement error, thus demonstrating uni-dimensionality and a high convergent validity of the constructs (Table 1).

Table 1: Factor Loadings and Reliability

\begin{tabular}{|c|c|c|c|c|c|c|}
\hline Constructs & Item & Loadings & $\begin{array}{l}\text { Cronbach's } \\
\text { Alpha }\end{array}$ & RHO & $\begin{array}{l}\text { Composite } \\
\text { Reliability }\end{array}$ & AVE \\
\hline \multirow{5}{*}{$\begin{array}{l}\text { Convenience } \\
\left(\begin{array}{cl}(\mathrm{C})\end{array}\right)\end{array}$} & CV1 & 0.717 & 0.836 & 0.862 & 0.885 & 0.608 \\
\hline & $\mathrm{CV} 2$ & 0.645 & & & & \\
\hline & $\mathrm{CV} 3$ & 0.870 & & & & \\
\hline & CV4 & 0.790 & & & & \\
\hline & CV5 & 0.854 & & & & \\
\hline \multirow{5}{*}{$\begin{array}{l}\text { Economic } \\
\text { Benefit } \\
\text { (EB) }\end{array}$} & EB1 & 0.710 & 0.838 & 0.851 & 0.884 & 0.605 \\
\hline & EB2 & 0.714 & & & & \\
\hline & EB3 & 0.844 & & & & \\
\hline & EB4 & 0.832 & & & & \\
\hline & EB5 & 0.780 & & & & \\
\hline \multirow{4}{*}{$\begin{array}{l}\text { Intention } \\
\text { (INT) }\end{array}$} & INT1 & 0.842 & 0.806 & 0.866 & 0.869 & 0.626 \\
\hline & INT2 & 0.846 & & & & \\
\hline & INT3 & 0.790 & & & & \\
\hline & INT4 & 0.674 & & & & \\
\hline \multirow{5}{*}{$\begin{array}{l}\text { Perceived } \\
\text { Benefit } \\
(\mathrm{PB})\end{array}$} & PB1 & 0.760 & 0.863 & 0.866 & 0.902 & 0.649 \\
\hline & PB2 & 0.860 & & & & \\
\hline & PB3 & 0.835 & & & & \\
\hline & PB4 & 0.841 & & & & \\
\hline & PB5 & 0.723 & & & & \\
\hline \multirow{5}{*}{$\begin{array}{l}\text { Transaction } \\
\text { Process } \\
\text { (TP) }\end{array}$} & TP1 & 0.706 & 0.817 & 0.857 & 0.871 & 0.578 \\
\hline & TP2 & 0.815 & & & & \\
\hline & TP3 & 0.858 & & & & \\
\hline & TP4 & 0.777 & & & & \\
\hline & TP5 & 0.622 & & & & \\
\hline
\end{tabular}

Predictive power of the model is determined using the $\mathrm{R}$-square value $\left(\mathrm{R}^{2}\right)$, while the strength of the hypothesized relationships is determined using the path coefficients. Structural model assessment is confirmed by the bootstrapping procedure. 37.5 per cent of the variation in perceived benefits can be explained by the three named variables, which are convenience, economic benefit and transaction process while 15.5 per cent of the variance from perceived benefits can be explained by intention. The result of the hypothesis testing is summarised in Table 3. 
Table 2. Fornell-Larcker Criterion Results and Cross Loadings

\begin{tabular}{|c|c|c|c|c|c|}
\hline Construct & CV & EB & INT & PB & $\mathbf{T P}$ \\
\hline \multicolumn{6}{|c|}{ Fornell-larcker criterion } \\
\hline $\mathrm{CV}$ & $0.780 * *$ & & & & \\
\hline EB & $0.698 *$ & $0.778 * *$ & & & \\
\hline INT & $0.718^{*}$ & $0.778 *$ & $0.791 * *$ & & \\
\hline PB & $0.400 *$ & $0.592 *$ & $0.394 *$ & $0.805 * *$ & \\
\hline $\mathrm{TP}$ & $0.856^{*}$ & $0.846^{*}$ & $0.894 *$ & $0.435^{*}$ & $0.760 * *$ \\
\hline \multicolumn{6}{|c|}{ Cross loadings } \\
\hline CV1 & 0.717 & 0.597 & 0.688 & 0.294 & 0.773 \\
\hline CV2 & 0.645 & 0.448 & 0.586 & 0.234 & 0.622 \\
\hline CV3 & 0.870 & 0.598 & 0.569 & 0.384 & 0.693 \\
\hline CV4 & 0.790 & 0.476 & 0.438 & 0.268 & 0.571 \\
\hline CV5 & 0.854 & 0.586 & 0.544 & 0.350 & 0.689 \\
\hline EB1 & 0.414 & 0.710 & 0.361 & 0.583 & 0.443 \\
\hline EB2 & 0.575 & 0.714 & 0.573 & 0.311 & 0.627 \\
\hline EB3 & 0.555 & 0.844 & 0.636 & 0.455 & 0.666 \\
\hline EB4 & 0.541 & 0.832 & 0.791 & 0.456 & 0.798 \\
\hline EB5 & 0.686 & 0.780 & 0.730 & 0.405 & 0.817 \\
\hline INT1 & 0.510 & 0.745 & 0.842 & 0.424 & 0.765 \\
\hline INT2 & 0.624 & 0.689 & 0.846 & 0.293 & 0.774 \\
\hline INT3 & 0.639 & 0.531 & 0.790 & 0.240 & 0.708 \\
\hline INT4 & 0.564 & 0.401 & 0.674 & 0.221 & 0.556 \\
\hline PB1 & 0.366 & 0.456 & 0.305 & 0.760 & 0.367 \\
\hline PB2 & 0.350 & 0.484 & 0.347 & 0.860 & 0.359 \\
\hline PB3 & 0.306 & 0.470 & 0.302 & 0.835 & 0.326 \\
\hline PB4 & 0.380 & 0.498 & 0.364 & 0.841 & 0.400 \\
\hline PB5 & 0.200 & 0.475 & 0.262 & 0.723 & 0.293 \\
\hline TP1 & 0.765 & 0.542 & 0.491 & 0.280 & 0.706 \\
\hline TP2 & 0.538 & 0.804 & 0.808 & 0.448 & 0.815 \\
\hline TP3 & 0.698 & 0.737 & 0.763 & 0.352 & 0.858 \\
\hline $\mathrm{TP} 4$ & 0.713 & 0.577 & 0.691 & 0.271 & 0.777 \\
\hline TP5 & 0.645 & 0.448 & 0.586 & 0.234 & 0.622 \\
\hline
\end{tabular}

Table 3: Results of Hypothesis Testing

\begin{tabular}{|c|c|c|c|c|c|c|}
\hline Hypothesis & Relationship & $\begin{array}{l}\text { Standard } \\
\text { Beta (B) }\end{array}$ & $\begin{array}{l}\text { Standard } \\
\text { error }\end{array}$ & t-value & Results & $\mathbf{f}^{2}$ \\
\hline H1 & $\mathrm{PB} \rightarrow \mathrm{INT}$ & 0.394 & 0.068 & $5.810 * *$ & Significant & 0.184 \\
\hline $\mathrm{H} 2$ & $\mathrm{~EB} \rightarrow \mathrm{PB}$ & 0.806 & 0.112 & $7.208 * *$ & Significant & 0.294 \\
\hline H3 & $\mathrm{CV} \rightarrow \mathrm{PB}$ & 0.183 & 0.134 & 1.369 & $\begin{array}{l}\text { Not } \\
\text { significant }\end{array}$ & 0.014 \\
\hline $\mathrm{H} 4$ & $\mathrm{TP} \rightarrow \mathrm{PB}$ & -0.404 & 0.177 & $2.275 * * *$ & Significant & 0.038 \\
\hline
\end{tabular}




\section{Discussion and Conclusion}

This paper examines whether perceived benefits affect SME's intention to use Islamic crowdfunding platform and whether three variables; economic benefit, convenience and transaction process significantly influence perceived benefits of the Islamic crowdfunding platform. Based on the result, perceived benefits were found to have a significant relationship with intention. This result implies that the more users perceived the benefits of using the IAP, the higher their intention to use the platform. Economic benefit was found to have a positive and significant relationship with perceived benefits. This result is consistent with another study by Ryu (2018a). As fintech suggests a lower transaction and capital costs compared with traditional financial service, which benefiting customers, this result is predictable. In summary, the more SMEs perceived that using the IAP will have economic benefits, the higher their perceived benefits on using the platform.

Convenience has been found to have an insignificant relationship with perceived benefits. This result, although contradicts with previous study by Ryu (2018a), may offer further avenue for research extension whereby convenience factors of the platform may strongly influence the formation of intention, attitude, perceived ease of use and perceived usefulness other than perceived benefits (Cho and Sagynov, 2015; Tanadi et al., 2015; Matthew et al., 2013). According to (Ryu (2018a) and Abramova and Böhme (2016), the transaction process plays a key role in determining perceived benefits of online platform. However, the result of this paper found the contrary. This surprising result implies that SMEs do not consider smooth, efficient, and faster transaction speeds as the benefits of using the IAP.

Fintech platform providers can enhance the usage of the IAP among SMEs by focusing their attention on the economic benefits of using the platform and offering more added values, so that SMEs will conclude that the platform has more advantages than other fund seeking channels, including traditional forms of financing. This result contributes to the intentionfintech research by highlighting the factors affecting perceived benefits and intention to the crowdfunding platform. The result may explain what affects SMEs' intention to use the platform. This study also provides interesting foundation for further research. For example, researchers might look into the perceived risk perspective as risk exposure with fintech platform has emerged as one of the challenges in the fintech adoption rate. Further research should also analyse the extent to which this paper results generalize to other fintech platforms and sample sizes.

\section{References}

Abramova, S., and Rainer, B. (2016). Perceived Benefit and Risk as Multidimensional Determinants of Bitcoin Use: A Quantitative Exploratory Study. Proceedings of the Thirty-Seventh International Conference on Information Systems (ICIS 2016), 1-20. doi:10.1016/j.socscimed.2011.05.023.

Akroush, M. N., Majdy I. Z., Hana I. A., Nermeen A. A. (2018). Determinants of Purchasing Intentions of Energy-Efficient Products: The Roles of Energy Awareness and Perceived Benefits. International Journal of Energy Sector Management, 13 (1), 128148doi:10.1108/ijesm-05-2018-0009.

Akturan, U, and Nuray, T. (2012). Mobile Banking Adoption of the Youth Market: Perceptions and Intentions. Marketing Intelligence and Planning, 30 (4), 444-59. doi:10.1108/02634501211231928.

Alaa A., Finocracy, and Mirakhor, A. (2017). Accelerating Risk Sharing Finance via FinTech: NextGen Islamic Finance. The 1st International Colloquium on Islamic Banking and Islamic Finance, 1-10. 
Alaeddin, O. and Altounjy, R. (2018). Trust, technology awareness and satisfaction effect into the intention to use cryptocurrency among generation $\mathrm{Z}$ in Malaysia. International Journal of Pure and Applied Mathematics, 120(2), 7-10.

Cho, Y. C., and Esen, S. (2015). Exploring Factors That Affect Usefulness, Ease Of Use, Trust, And Purchase Intention In The Online Environment." International Journal of Management \& Information Systems, $19 \quad$ (21-36) 7763-7769, doi:10.1021/acs.inorgchem.8b00815.

Dietrich, A., and Simon, A. (2017) Crowdfunding Monitoring Switzerland 2017.

Fornell, C., and Larcker, D. F. (1981). Evaluating Structural Equation Models with Unobservable Variables and Measurement Error. Journal of Marketing Research, 18, (1), 39-50, doi:10.2307/3151312.

Fishbein, M. and Ajzen, I. (1975), Belief, Attitude, Intention, and Behavior: An Introduction to Theory and Research, Addison-Wesley, Reading, MA.

Gałkiewicz, D. P., and Gałkiewicz, M. 2018. Crowdfunding Monitor 2018: An Overview of European Projects Financed on Startnext and Kickstarter Platforms between 2010 and Mid-2017.

Hsu, S-H, and Bayarsaikhan, B-E. (2012) Factors Influencing on Online Shopping Attitude and Intention of Mongolian Consumers. The Journal of International Management Studies, 7 (2), 167-76.

KPMG. (2018). The Pulse of Fintech 2018: Biannual Global Analysis of Investment in Fintech. no. July.

Lee, M. C. (2009). Factors Influencing the Adoption of Internet Banking: An Integration of TAM and TPB with Perceived Risk and Perceived Benefit. Electronic Commerce Research and Applications, 8, 130-41, doi:10.1016/j.elerap.2008.11.006.

Lian, H. N. (2016). New Fintech Regulatory Framework in the Making.

Mackenzie, A. (2015). The Fintech Revolution. London Business School Review, 26 (3), 5053.

Matthew, T. L, James, L. B., Cheng Shi, Gui, Rongwei, C., TingHsiang, T. (2013). Perceived Benefits, Perceived Risk, and Trust:Influences on Consumers' Group Buying Behaviour. Asia Pacific Journal of Marketing and Logistics, 25 (2). 225-48, doi:10.1108/13555851311314031.

Nunnally, J. C. (1987). Psychometric Theory. 2nd ed, McGraw-Hill.

OECD. (2018). Financing SMEs and Entrepreneurs 2014.doi:10.1787/fin_sme_ent-2014-en.

Oxera Economics Council. (2015). Benefits of Online Platforms. no. October, 2015, http://www.oxera.com/getmedia/89afcf75-95f0-4b8f-ab3e-d463e81e5f46/Thebenefits-of-online-platforms-technical-appendix-(October-2015).pdf.aspx.

Ryu, H-S. (2018). Understanding Benefit and Risk Framework of Fintech Adoption: Comparison of Early Adopters and Late Adopters. Proceedings of the 51st Hawaii International Conference on System Sciences, 3864-3873. https://scholarspace.manoa.hawaii.edu/bitstream/10125/50374/1/paper0487.pdf.

SME. (2016). Access to Finance. http://www.smecorp.gov.my/images/SMEAR/latest/Chapter6.pdf.

Tanadi, T., Samadi, B. and Gharleghi, B. (2015). The Impact of Perceived Risks and Perceived Benefits to Improve an Online Intention among Generation-Y in Malaysia. Asian Social Science, 11 (26), 226-38, doi:10.5539/ass.v11n26p226.

Tanduklangi, A. (2017). Determinants of User Intention in Using E-Learning Technology in Indonesian Context: An Empirical Study. Mediterranean Journal of Social Sciences, 8, (3), 69-77, doi:10.5901/mjss.2017.v8n3p69. 
The Organisation for Economic Co-operation and Development (OECD). (2018). SME Policy Index: Asean 2018. 2018, https://asean.org/wp-content/uploads/2018/08/ReportASEAN-SME-Policy-Index-2018.pdf.

Zahid, A. Z. M. (2018). Assistant Governor's Welcoming Remarks at the Islamic Finance Rendezvous Series. Bank Negara Malaysia.

---. (2018) What Makes Users Willing or Hesitant to Use Fintech?: The Moderating Effect of User Type.” Industrial Management \& Data Systems, 118 (3), 541-69. 